\title{
Incidental Detection of Carcinoma In-situ in Fibroadenoma of the Breast in a Young Woman: A Rare Finding
}

\author{
Atul Tiwari ${ }^{1}$, Brij Mohan K. Singh ${ }^{2}$, Shubham Varshney ${ }^{2}$, Mohan L. Yadav ${ }^{1}$ \\ 1. Department of Pathology, Mahatma Gandhi Medical College \& Hospital, Jaipur, IND 2. Department of Pathology, \\ Kasturba Medical College, Manipal, IND
}

Corresponding author: Atul Tiwari, atultiwari88@gmail.com

\begin{abstract}
Fibroadenoma, being a very common benign tumor of the breast in young females, does not pose any threat and, thus, can be treated with lumpectomy. Breast cancer arising within a fibroadenoma is a rare phenomenon, but detecting these neoplasms is of utmost importance for complete treatment and follow-up. These lesions are an incidental finding in a lumpectomy specimen done for fibroadenoma breast.

A 28-year-old female presented with multiple bilateral lumps for eight years. The lumps were mobile, nontender, and slowly growing, with no nipple discharge, no axillary lymphadenopathy, and no family history. The diagnosis of a benign lesion suggestive of fibroadenoma was given on ultrasonography (USG) and fineneedle aspiration cytology (FNAC). The patient underwent lumpectomy and the excised tissues were subjected to histopathological examination. Grossly, multiple, well-circumscribed, encapsulated masses, with the largest measuring $4 \times 2.5 \times 2 \mathrm{~cm}$ were noted. All masses showed homogenous grey-white areas with slit-like spaces. On microscopy, predominant areas were consistent with fibroadenoma, with few foci showing the features of ductal carcinoma in situ (DCIS) with nests of cells having pleomorphic nuclei, prominent nucleoli with atypical mitosis, a cribriform pattern, and comedo necrosis.
\end{abstract}

This highlights the rare association of fibroadenoma and carcinoma in situ, thus, a careful and extensive sampling of the tissue is required to prevent the false negative diagnosis by pathologists.

Received 12/18/2018

Review began 12/23/2018 Review ended 12/24/2018 Published 12/31/2018

\section{() Copyright 2018}

Tiwari et al. This is an open access article distributed under the terms of the Creative Commons Attribution License CC-BY 3.0., which permits unrestricted use, distribution, and reproduction in any medium, provided the original author and source are credited.
Categories: Pathology

Keywords: fibroadenoma, carcinoma in situ, ductal carcinoma in situ

\section{Introduction}

A fibroadenoma, being a very common benign tumor of the breast in young females, does not pose any threat and, thus, can be treated with lumpectomy [1]. Breast cancer arising within fibroadenoma is a rare phenomenon, but detecting these neoplasms is of utmost importance for complete treatment and follow-up. These lesions are an incidental finding in a lumpectomy specimen done for fibroadenoma breast [2].

\section{Case Presentation}

A 28-year-old female presented with multiple bilateral breast lumps for eight years. The lumps were mobile, non-tender, and slowly growing. On examination, multiple freely mobile lumps in both breasts (eight on the right side, four on the left side) with well-defined margins, firm consistency, and a smooth surface were identified. There was no tenderness or local rise in temperature, no history of ulcers, puckering, dimpling, or swelling. They were not associated with any change during the menstrual cycle. There was no family history of breast carcinoma. Ultrasonography (USG) showed multiple hypoechoic lesions suggestive of fibroadenoma (Figure 1). 


\section{Cureus}

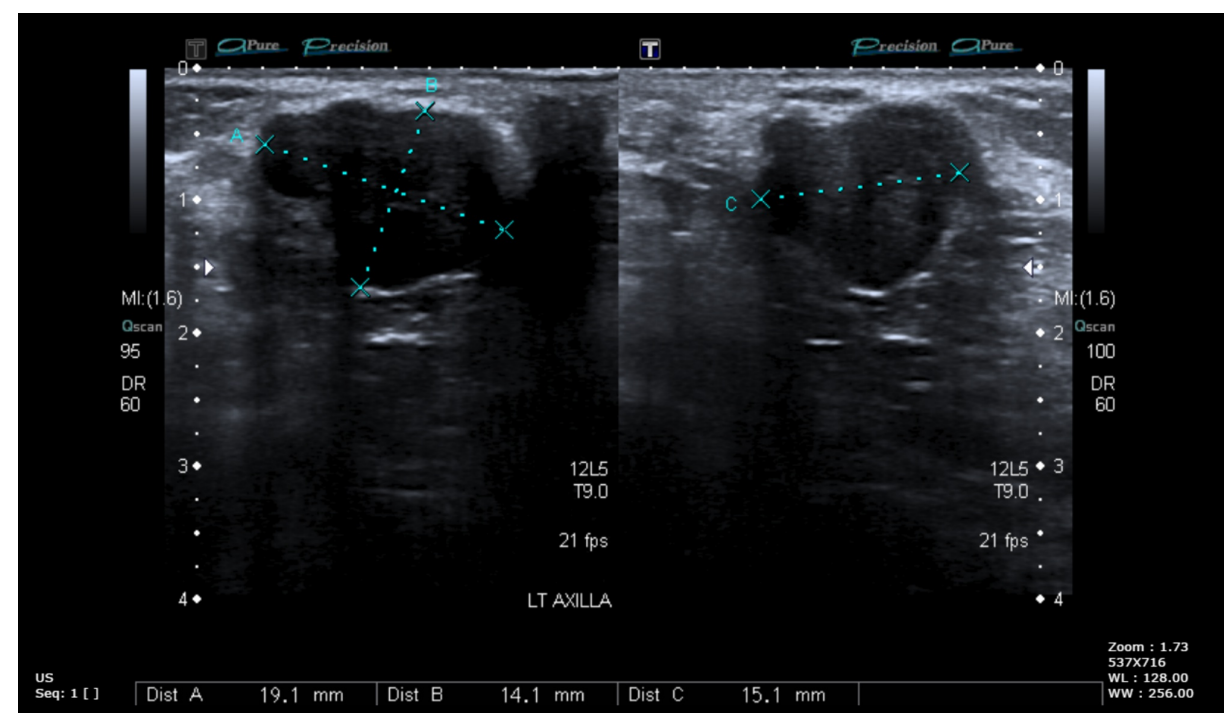

FIGURE 1: USG: Hypoechoic lesion

USG: ultrasonography

Similarly, fine needle aspiration cytology (FNAC) showed multiple cohesive clusters of branching papillary fronds suggestive of fibroadenoma (Figures 2-3).

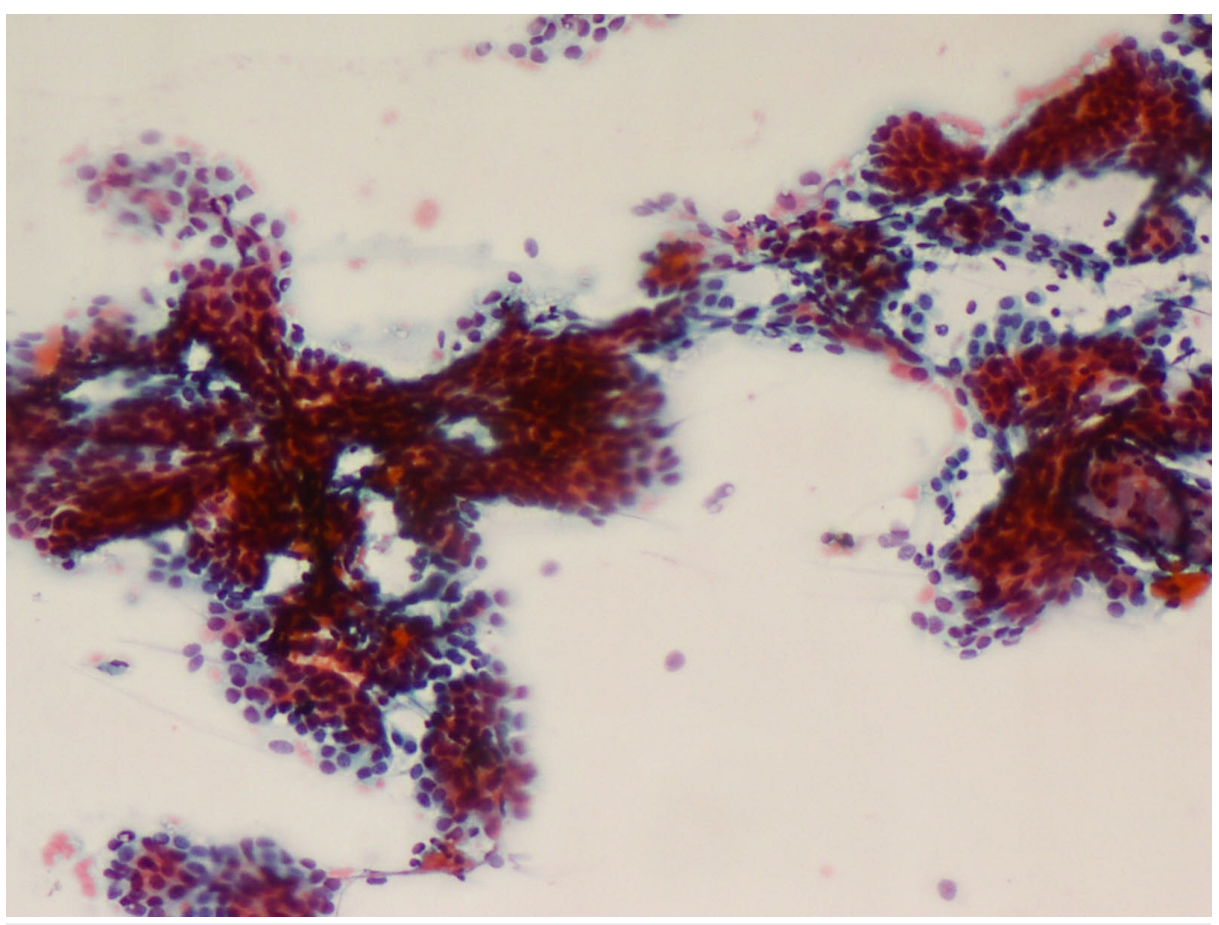

FIGURE 2: FNAC: Cohesive clusters with branching papillary fronds (PAP $\times 100)$

PAP: Papanicolaou stain; FNAC: fine-needle aspiration cytology 


\section{Cureus}

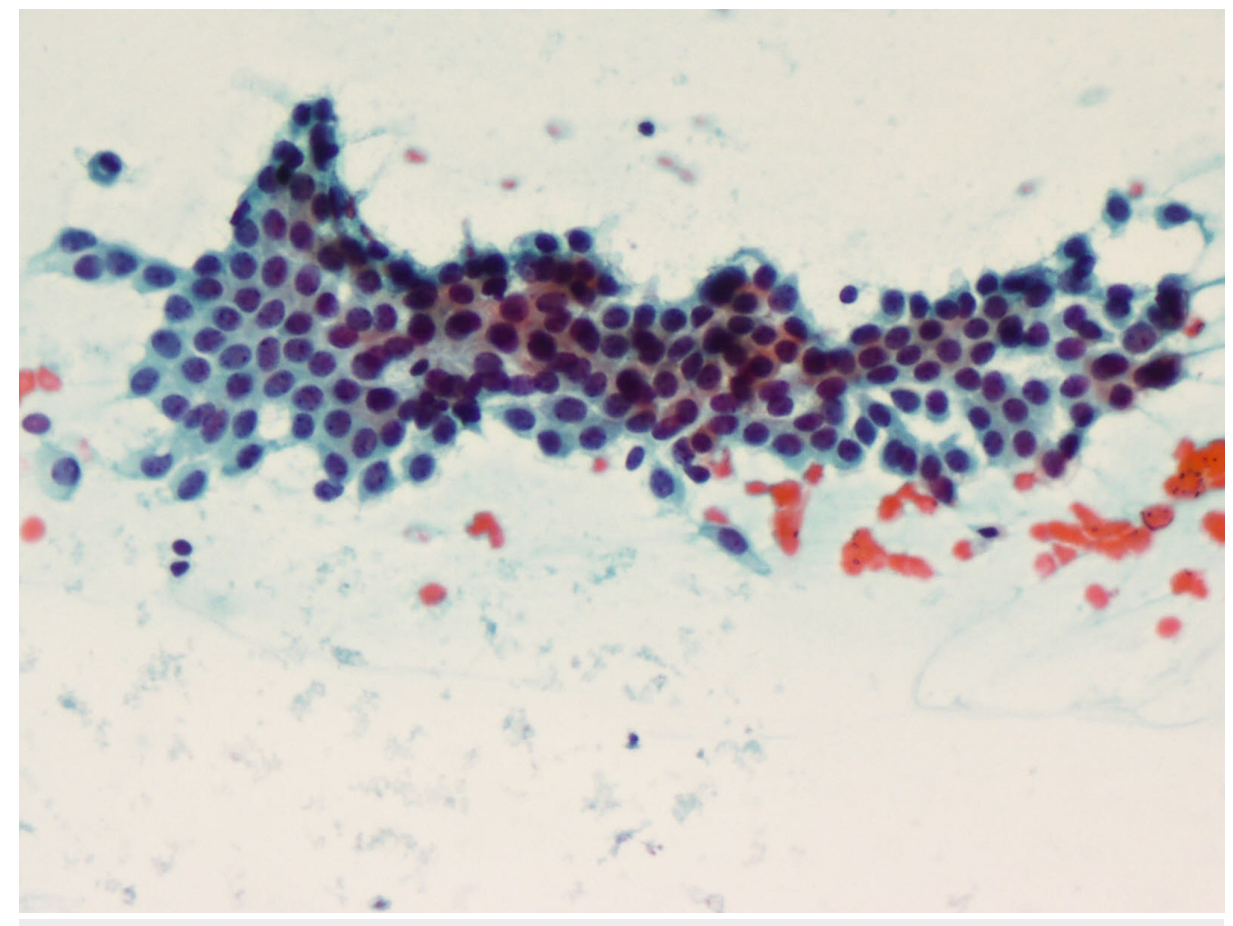

FIGURE 3: FNAC: Cohesive clusters with branching papillary fronds (PAP $\times 200)$

PAP: Papanicolaou stain; FNAC: fine-needle aspiration cytology

The patient underwent lumpectomy, and the excised specimens were sent for histopathological examination. Gross examination of the excised specimens showed multiple, circumscribed, encapsulated masses with the largest measuring $4 \times 2.5 \times 2 \mathrm{~cm}$. The cut section showed slit-like spaces surrounded by greywhite areas (Figure 4).

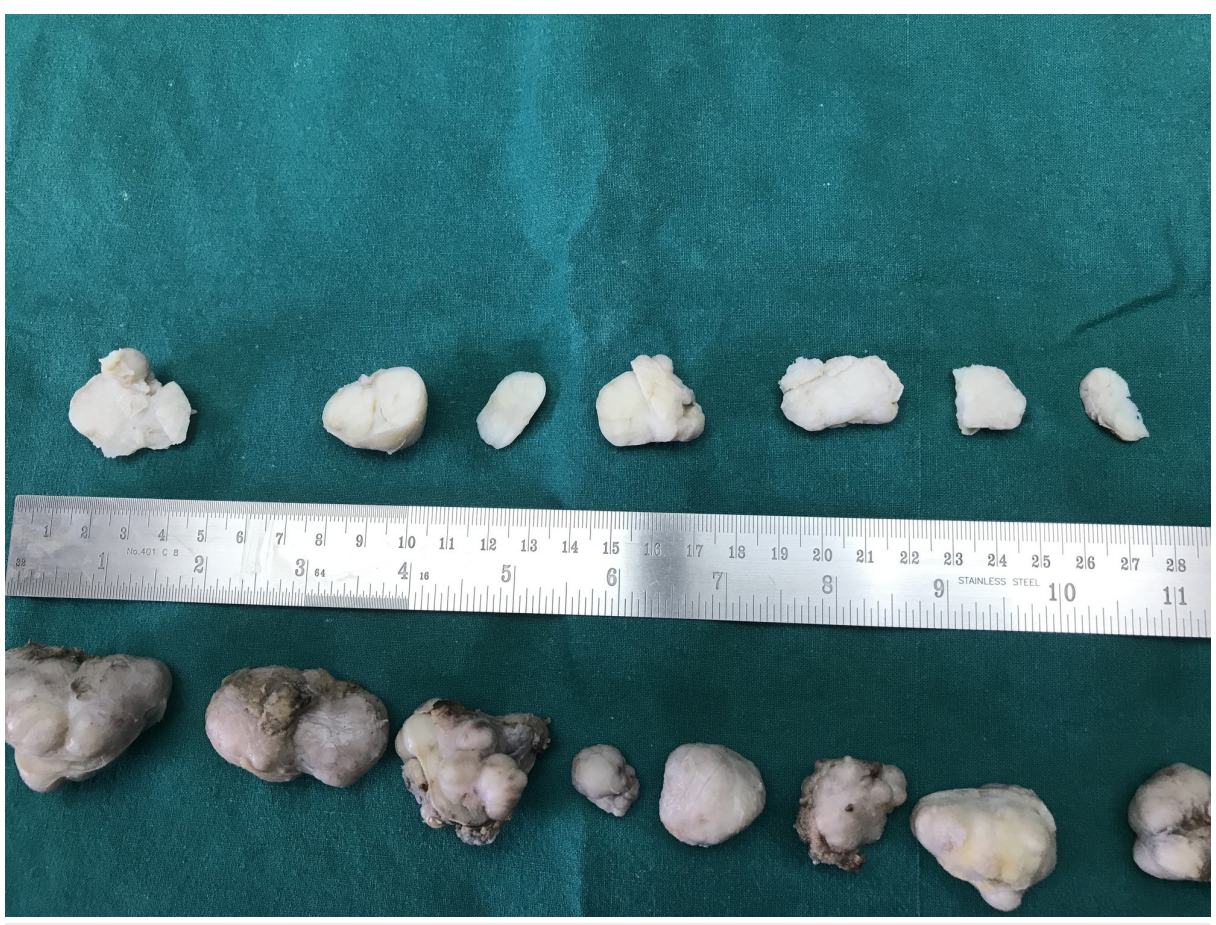

FIGURE 4: Gross: Multiple, well-circumscribed encapsulated masses

Microscopy predominantly showed an encapsulated tumor composed of proliferating acini lined by 


\section{Cureus}

epithelial and myoepithelial cells, many of which are compressed by fibrous stroma, which is myxoid in areas (Figures 5-7). At the foci, there were areas showing nests of malignant cells having pleomorphic nuclei, prominent nucleoli, and eosinophilic cytoplasm with atypical mitosis, a cribriform pattern, and comedo necrosis, suggestive of ductal carcinoma in situ (Figures 8-10). Stroma surrounding the carcinoma was normal without any evidence of atypical cell invasion.

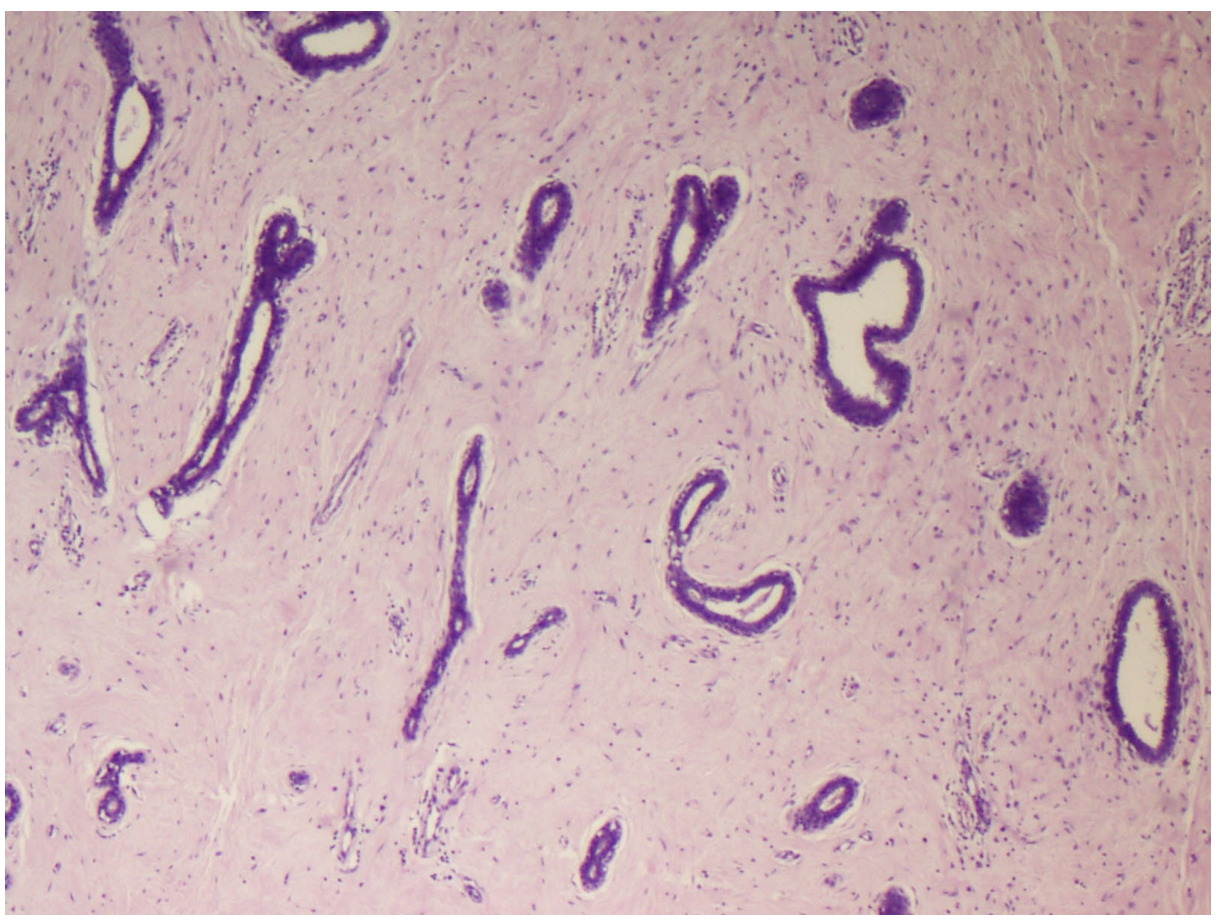

FIGURE 5: Fibroadenoma with compressed ducts (H\&E x100)

H\&E: hematoxylin and eosin

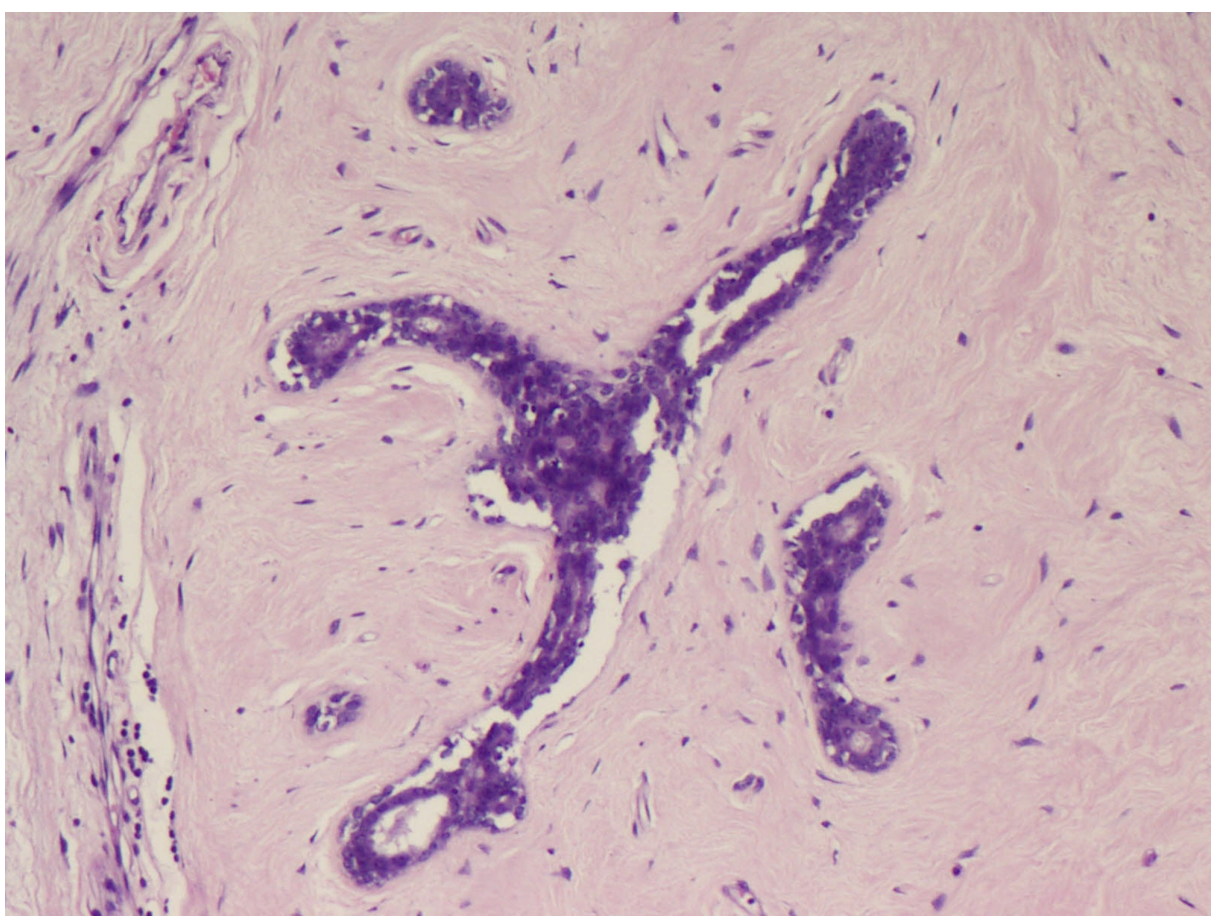

FIGURE 6: Fibroadenoma with compressed ducts (H\&E x200)

H\&E: hematoxylin and eosin 


\section{Cureus}

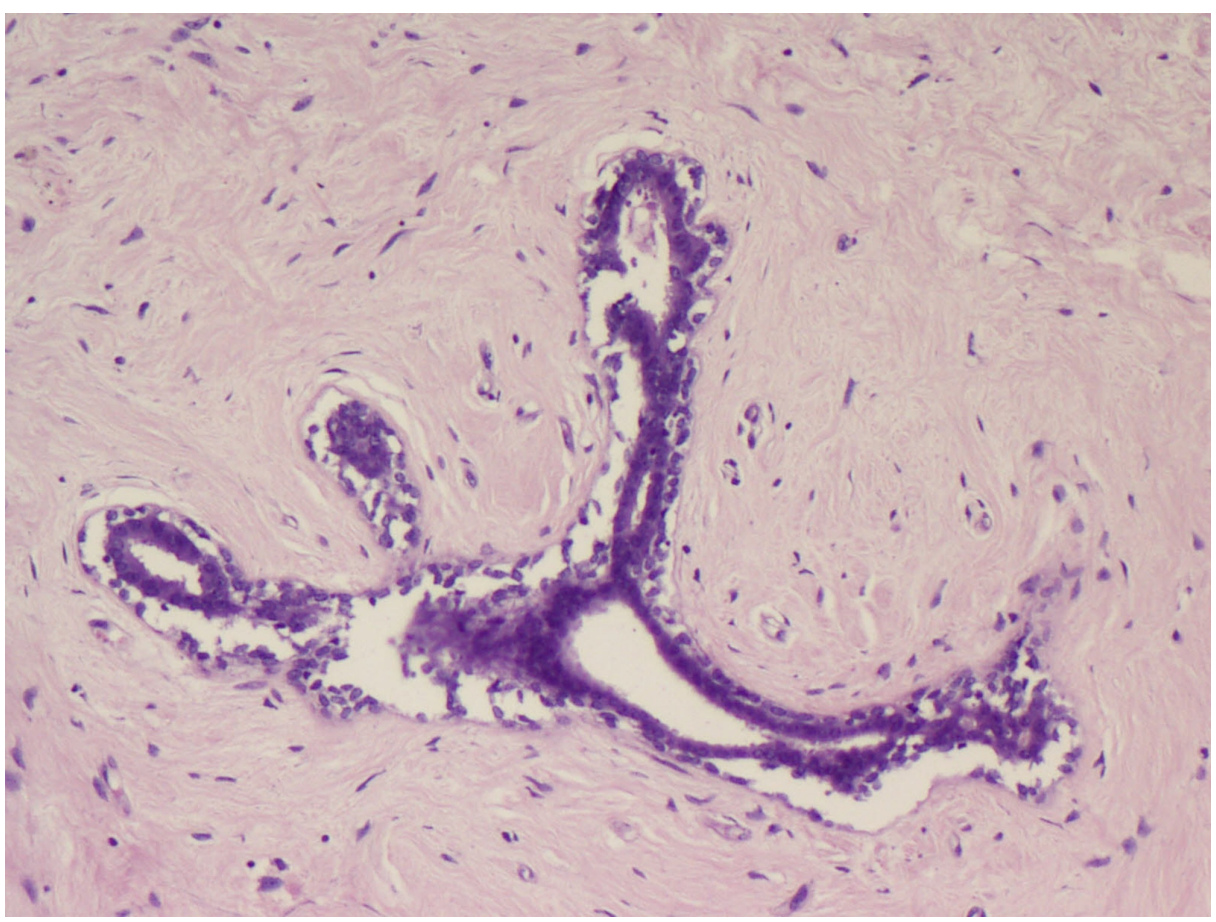

FIGURE 7: Fibroadenoma with compressed ducts (H\&E x200)

H\&E: hematoxylin and eosin

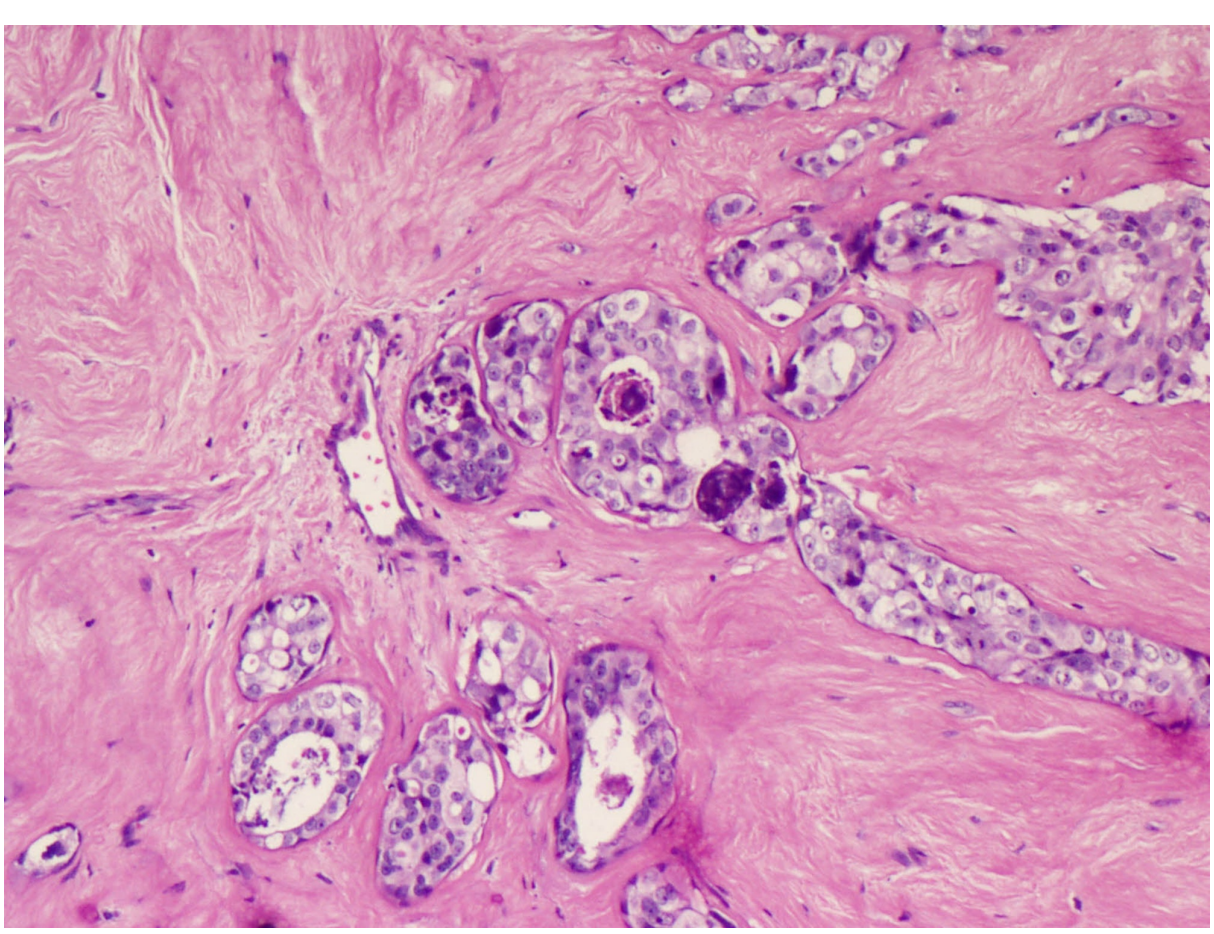

FIGURE 8: Cellular proliferation with comedo necrosis (H\&E x100)

H\&E: hematoxylin and eosin 


\section{Cureus}

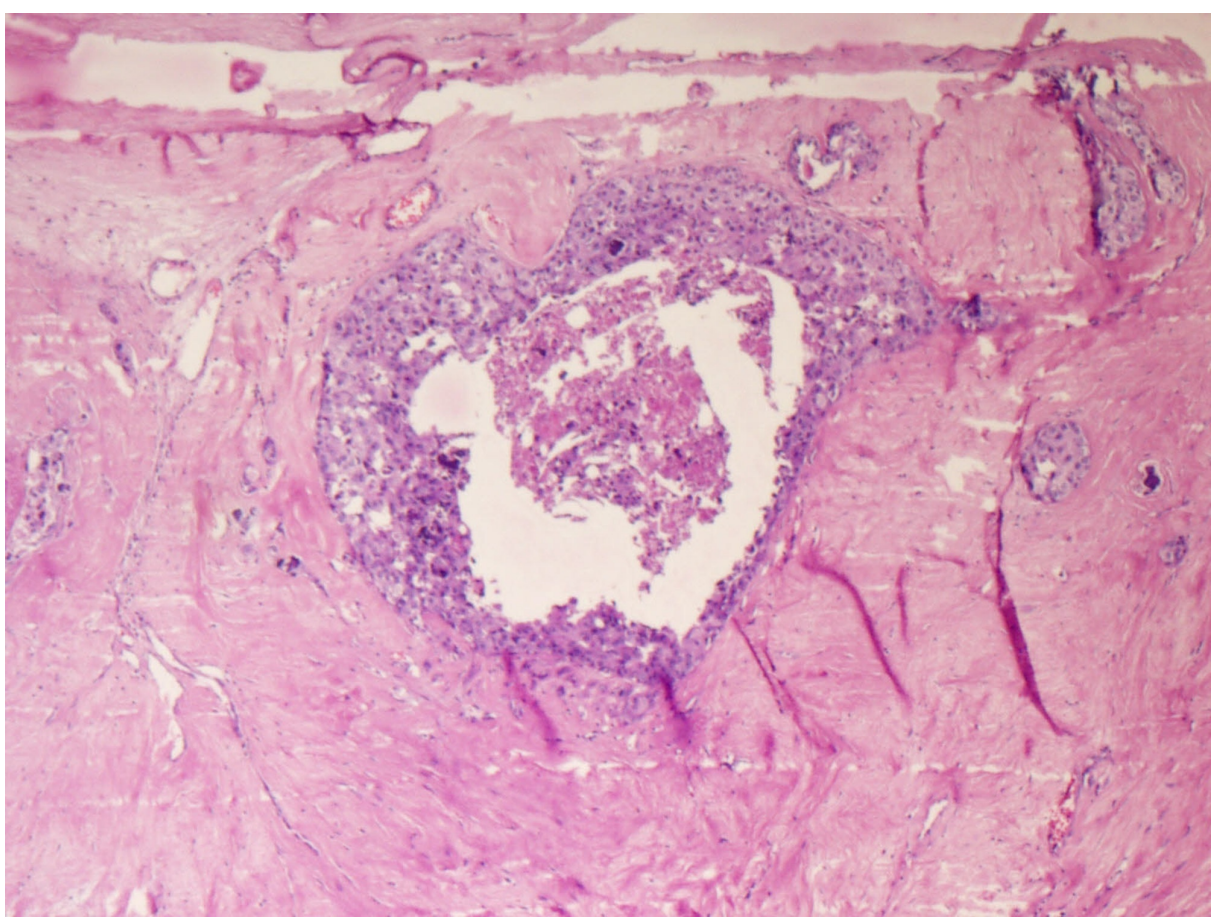

FIGURE 9: Cellular proliferation with comedo necrosis (H\&E x100)

H\&E: hematoxylin and eosin

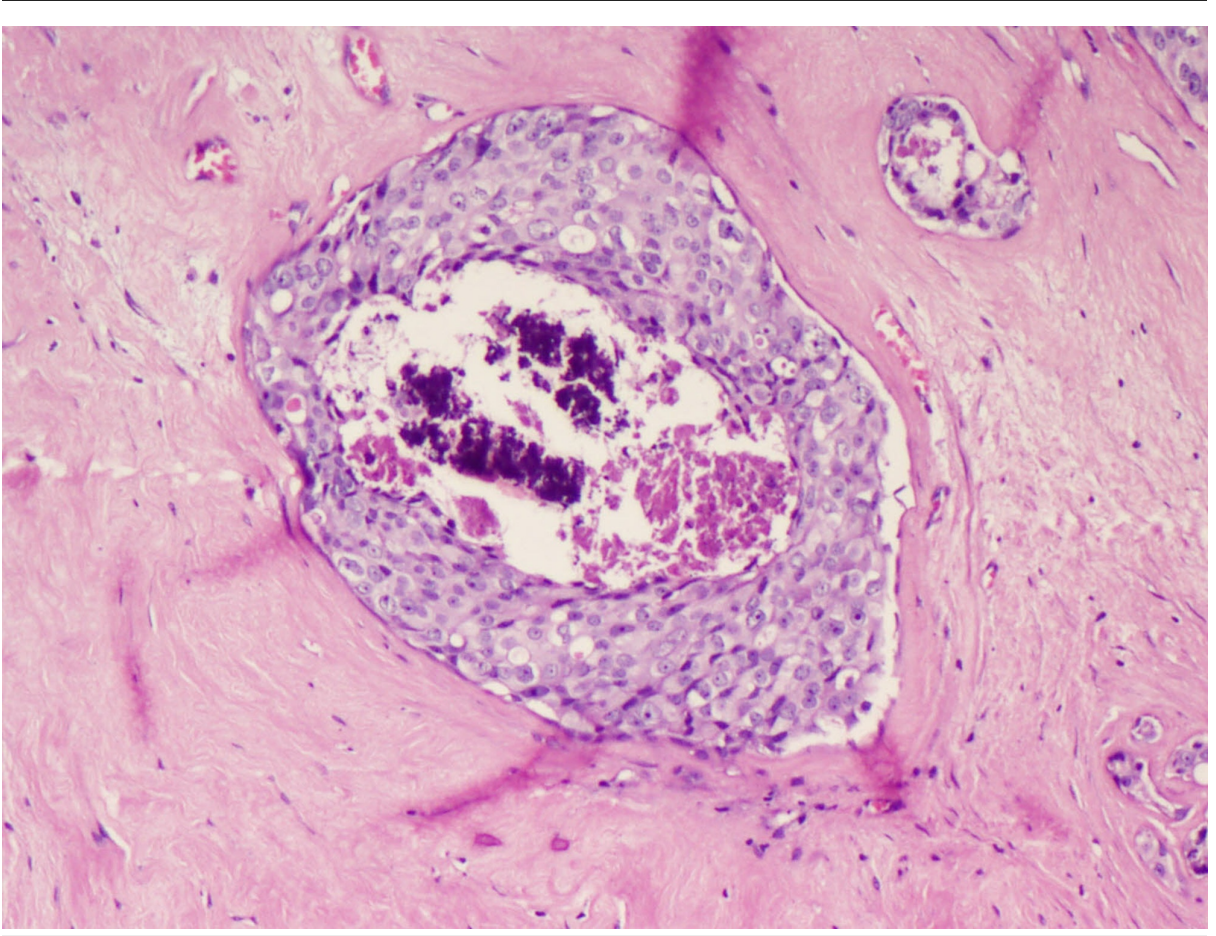

FIGURE 10: Cellular proliferation with comedo necrosis (H\&E x200)

H\&E: hematoxylin and eosin

Discussion

A fibroadenoma is a common benign tumor of the breast with a peak incidence at the second and third decades of age. A fibroadenoma must be differentiated from benign phyllodes tumor, as carcinomas arising from a phyllodes tumor are also reported in the literature. Fibroadenomas can be classified as simple or 
complex. Clinically, fibroadenomas present with a lump in the breast, which was the presenting complaint in this case. A preoperative diagnosis of carcinoma arising from these lesions is difficult because of the close resemblance of the presenting features with benign fibroadenoma [3-4]. To evaluate breast lesions, triple tests were done and include clinical examination, USG, and FNAC $[1,5]$.

The characteristic USG features of fibroadenomas include round, hypoechoic lesions with smooth borders and normal surrounding areas while in case of malignancy, the features are irregular shape and margins, hypoechogenicity, and posterior acoustic shadowing [6].

The FNAC findings of fibroadenoma are clusters of branching papillary fronds of benign ductal epithelial cells, myoepithelial cells, and sparse stromal fragments in a fibromyxoid background. While in the case of malignancy, FNAC shows a high nuclear-cytoplasmic ratio (N:C ratio) with pleomorphism and hyperchromatic nuclei.

In the present case, these features were not present on FNAC, therefore, the diagnosis was given as a benign lesion. Because of the limitations of FNAC for selective sampling, the confirmation can only be done by a histopathological examination of the excised specimen. In the present case, the diagnosis was evident only on a histopathological examination.

The diagnostic criteria of DCIS within fibroadenomas require showing at least one of the following findings: (a) intraductal carcinoma focus, seen in the adjacent breast tissue, or (b) intraductal proliferative lesions within fibroadenomas show cancer-characteristic findings, e.g., epithelial necrosis [7].

Definitive treatment consists of surgery with or without radio or chemotherapy. Surgical management depends on the stage at the time of presentation and the presence of axillary or distant metastasis [8]. In the presenting case, excision with breast conservative surgery was done for in-situ carcinoma arising from fibroadenomas. Prognosis is good in cases of early detection.

\section{Conclusions}

This case highlights the rare association of fibroadenoma and carcinoma in situ. In this case, USG and FNAC revealed only multiple fibroadenomas. The carcinoma was detected incidentally on histopathological examination. Therefore, a careful and extensive sampling of the tissue is required to prevent a false negative diagnosis by pathologists.

\section{Additional Information \\ Disclosures}

Human subjects: Consent was obtained by all participants in this study. Conflicts of interest: In compliance with the ICMJE uniform disclosure form, all authors declare the following: Payment/services info: All authors have declared that no financial support was received from any organization for the submitted work. Financial relationships: All authors have declared that they have no financial relationships at present or within the previous three years with any organizations that might have an interest in the submitted work. Other relationships: All authors have declared that there are no other relationships or activities that could appear to have influenced the submitted work.

\section{References}

1. Kuijper A, Mommers EC, van der Wall E, van Diest PJ: Histopathology of fibroadenoma of the breast. Am J Clin Pathol. 2001, 115:736-742. 10.1309/F523-FMJV-W886-3J38

2. Abu-Rahmeh Z, Nseir W, Naroditzky I: Invasive ductal carcinoma within fibroadenoma and lung metastases . Int J Gen Med. 2012, 5:19-21. 10.2147/IJGM.S26115

3. Kuijper A, Preisler-Adams SS, Rahusen FD, Gille JJ, van der Wall E, van Diest PJ: Multiple fibroadenomas harbouring carcinoma in situ in a woman with a family history of breast/ovarian cancer. J Clin Pathol. 2002, 55:795-797. 10.1136/jcp.55.10.795

4. Sarela AI, Madvanur AA, Soonawala ZF, Shah HK, Pandit AA, Samsi AB: Carcinoma in a fibroadenoma . J Postgrad Med. 1995, 41:19-20. Accessed: December 19, 2018: http://www.jpgmonline.com/text.asp? 1995/41/1/19/473.

5. Rao S, Latha PS, Ravi A, Thanka J: Ductal carcinoma in a multiple fibroadenoma: diagnostic inaccuracies . J Cancer Res Ther. 2010, 6:385-387. 10.4103/0973-1482.73350

6. Skaane P, Engedal K: Analysis of sonographic features in the differentiation of fibroadenoma and invasive ductal carcinoma. AJR Am J Roentgenol. 1998, 170:109-114. 10.2214/ajr.170.1.9423610

7. Kwon MJ, Park HR, Seo J, et al.: Simultaneous occurrence of ductal carcinoma in situ within juvenile fibroadenoma in both breasts: a brief case report. Korean J Pathol. 2014, 48:164-166. 10.4132/KoreanJPathol.2014.48.2.164

8. Ooe A, Takahara S, Sumiyoshi K, Yamamoto H, Shiba E, Kawai J: Preoperative diagnosis of ductal carcinoma in situ arising within a mammary fibroadenoma: a case report. Jpn J Clin Oncol. 2011, 41:918-923. 10.1093/jjco/hyr075 